\title{
Effect of Charcoal Broiling on the Formation of Volatile Compounds in Gamma-Irradiated Dakgalbi, a Korean Chicken-Based Food
}

\author{
Geon-Ok Kang ${ }^{1}$, Young-Min Yoon, Jae-Kyung Kim, Beom-Seok Song, Eui-Baek Byun, Jae-Hun Kim, \\ Ju-Woon Lee, and Jong-Heum Park* \\ Advanced Radiation Technology Institute, Korea Atomic Energy Research Institute, Jeongeup 580-185, Korea \\ ${ }^{1}$ Department of Nutrition \& Culinary Science, Hankyong National University, Ansung 456-749, Korea
}

\begin{abstract}
The purpose of this study is to evaluate the change of volatile compounds in Dakgalbi cooked by charcoal broiling. Fresh deboned and marinated chicken meat was cooked by electric-pan frying or charcoal broiling and subsequently irradiated with a dose of 0,10 and $20 \mathrm{kGy}$. Volatile components from Dakgalbi were analyzed using solid phase micro-extraction gas chromatography - mass spectrometry (SPME GC-MS) and identified through the comparison of mass spectrum database. SPME GC-MS analysis shows that a total of 32 volatiles were identified. Among them, aldehydes such as hexanal and octanal, which have relevance to off-flavors such as green, paint, metallic, bean and rancid were detected in Dakgalbi cooked by both methods. However, the contents were less detected in the Dakgalbi cooked by charcoal broiling than in the Dakgalbi cooked by electric-pan frying. Gamma-irradiation caused the change in the formation of these aldehydes in cooked Dakgalbi. The irradiation significantly increased the contents of hexanal and octanal in Dakgalbi cooked by electric-pan frying and a similar increase was found in Dakgalbi cooked by charcoal broiling. However, the contents of the off-flavors were much less in the latter. The results suggest that charcoal broiling might be more effective than electric-pan frying for the reduction of the contents of off-flavor such as hexanal and octanal increased in Dakgalbi by gamma-irradiation.
\end{abstract}

Key words: Dakgalbi, gamma-irradiation, hexanal, octanal, off-flavor

\section{Introduction}

Dakgalbi is a popular chicken-based food in Korea. This food is made by cooking marinated chicken with lots of vegetables such as cabbage, sweet potatoes, scallions, onions; rice cake (Tteok); Korean chili paste (Gochugang). The common way to prepare Dakgalbi is stirfrying and charcoal broiling. Stir-frying is to cook marinated Dakgalbi with those ingredients on an iron pan and charcoal broiling is directly to grill Dakgalbi with the ingredients on charcoal fire. However, as Dakgalbi is commercially prepared, stir-frying is becoming more general than charcoal broiling. As Dakgalbi is prepared using high-protein chicken, and lots of high-dietary fiber and low-calorie vegetables, it is known to be a healthy food.

However, despite its popularity, Dakgalbi has a short shelf life as a cooked food. One of these reasons is due to

\footnotetext{
*Corresponding author: Jong-Heum Park, Advanced Radiation Technology Institute, Korea Atomic Energy Research Institute, Jeongeup 580-185, Korea. Tel: 82-63-570-3244, Fax: 82-63570-3218, E-mail: jhpark21@kaeri.re.kr
}

the initial bacterial contamination level of the chicken and red pepper paste. Korean chili paste in particular has been reported to be contaminated with a high level of thermoresistant bacteria such as Bacillus spp. (over 6 Log CFU/ $\mathrm{g}$ of red pepper paste) (Yoon et al., 2009). Therefore, the control of bacterial contamination on preparing Dakgalbi becomes a critical factor affecting its quality and hygienic safety.

Ionizing radiation is an effective food processing technology that can prevent food poisoning against harmful pathogens (Rajkowski and Thayer, 2000; Serrano et al., 1997). Unlike heat treatment, this technology can expand the shelf life of foods by eliminating bacteria present in foods without changing the nutritional value (Ahn et al., 2004; Farkas, 2006; WHO, 1999). Numerous studies using chicken demonstrate that ionizing radiation can improve the shelf life with no negative effects on their nutritional and sensory properties (Gomes et al., 2003; Javanmard et al., 2006; Mckay et al., 1997). Recent research performed by our group also showed that gamma-irradiation enhances the shelf life of cooked Dakgalbi (Yoon et al., 2012). However, as ionizing radiation can induce the generation 
of radiation-specific off-flavor in foods (Yook et al., 1998), it requires a combination with other food processing methods to alleviate the formation of the off-flavor.

In this study, the effect of gamma-irradiation on the change of volatile compounds in Dakgalbi cooked by charcoal broiling and the effects of the cooking condition on the formation of off-flavors in Dakgalbi were investigated.

\section{Material and Methods}

\section{Sample preparation}

Deboned fresh chicken was purchased from Harim Co. (Korea). As materials for the preparation of Dakgalbi sauce, Gochugang (CJ Co., Korea), crushed garlic (Dadam, CJ Co., Korea), soy sauce (Monggo Co., Korea), oligo-saccharides (CJ Co., Gyeonggido), saccharide (CJ Co., Gyeonggido), curry powder and turmeric powder (Emart, Korea) were procured from a local market in Jeongeup-si in South Korea. Carboxen-polydimethylsiloxan (CAR/PDMS) fiber for SPME GC-MS analysis was obtained from Supelco Co. (USA).

\section{Preparation of Dakgalbi}

The chicken was diced into small pieces $(2 \times 5 \mathrm{~cm})$ and cooked after marinating with Dakgalbi sauce composed of $45 \%(\mathrm{w} / \mathrm{v})$ red pepper paste, $22.5 \%(\mathrm{w} / \mathrm{v})$ water, $10 \%$ $(\mathrm{w} / \mathrm{v})$ corn syrup, $5 \%(\mathrm{w} / \mathrm{v})$ garlic, $5 \%(\mathrm{w} / \mathrm{v})$ soy sauce, $5 \%(\mathrm{w} / \mathrm{v})$ sugar, $4 \%(\mathrm{w} / \mathrm{v})$ ginger, $2.5 \%(\mathrm{w} / \mathrm{v})$ turmeric powder and $1 \%(\mathrm{w} / \mathrm{v})$ curry powder. To be exact, $1,200 \mathrm{~g}$ of diced chicken was seasoned with $300 \mathrm{~g}$ of Dakgalbi sauce for $2 \mathrm{~h}$ at $4^{\circ} \mathrm{C}$. The marinated Dakgalbi was then divided into 2 aliquots. One was used for the electric-pan frying and other was for the charcoal broiling. For the electric-pan frying (NU-VUE-3 Cooker, USA), the aliquot was cooked for 12 min until its central temperature achieved $70^{\circ} \mathrm{C}$. The other aliquot was charcoal-broiled on a spit (DK-E8-003; Daeil Co., Korea) for 12 min until its central temperature achieved $70^{\circ} \mathrm{C}$. The cooked Dakgalbi samples were cooled under room temperature and then immediately aseptically vacuum-packed in sterilized aluminum-laminated vacuum bags (low-density polyethylene; meting point, $120^{\circ} \mathrm{C}$; density, $0.92 \mathrm{~g} / \mathrm{cm}^{3}$ ) and followed by freezing at $-20^{\circ} \mathrm{C}$ in refrigerator. The electric-pan-fried Dakgalbi sample was used as a control for comparing only the contents of hexanal and octanal formed in charcoal-broiled Dakgalbi sample.

\section{Gamma irradiation}

Gamma irradiation of cooked Dakgalbi was carried out using a cobalt-60 irradiator (IR-221; MDS Nordion International Co. Ltd., Canada) at the Advanced Radiation Technology Institute of the Korea Atomic Energy Research Institute (Korea). The frozen Dakgalbi samples were irradiated with absorbed doses of 10 and $20 \mathrm{kGy}(10 \mathrm{kGy} / \mathrm{h})$ in a dry-ice packed box. The determination of the absorbed dose of irradiated cooked Dakgalbi was performed using a $5 \mathrm{~mm}$ diameter alanine dosimeter (Bruker Instruments, Germany), calibrated against an international standard set by the International Atomic Energy Agency (Austria). The error of the total adsorbed doses in the Dakgalbi samples was within $2 \%$. The irradiated samples were kept at $-20^{\circ} \mathrm{C}$ again prior to SPME GC-MS analysis.

\section{Extraction of volatile compounds from Dakgalbi}

Dakgalbi samples were finely chopped with a knife, and $2 \mathrm{~g}$ of each sample was placed into a $20 \mathrm{~mL}$ of headspace vial, and sealed with a septum and an aluminum cap. Carboxen-polydimethylsiloxan (CAR/PDMS, $75 \mathrm{~mm}$ ) fiber was used for the extraction of volatile components. The fiber was preconditioned before the analyses according to the instructions by the manufacturer (Supelco Co., USA).

Volatiles were extracted by exposing CAR/PDMS fiber to the headspace of the sample vial maintained at $50^{\circ} \mathrm{C}$ for $20 \mathrm{~min}$. For the thermal desorption, the fiber was immediately inserted into GC injector, and a desorption time of $1.5 \mathrm{~min}$ at $250^{\circ} \mathrm{C}$ was used in split mode (10:1).

\section{Analysis of GC-MS}

Volatile components from Dakgalbi were analyzed using GC (Varian Star 3400 CX; Agilent Technology Inc., USA) fitted with an HP-5S capillary column (crosslinked 5\% diphenyl and 95\% dimethylpolysiloxane; $30 \mathrm{~m}, 0.32 \mathrm{~mm}$ inner diameter, $0.32 \mathrm{~mm}$ film thickness; Agilent Technology Inc., USA). The GC oven temperature program consisted of $32^{\circ} \mathrm{C}$ for $2 \mathrm{~min}, 32-70^{\circ} \mathrm{C}$ at $2^{\circ} \mathrm{C} / \mathrm{min}, 70-200^{\circ} \mathrm{C}$ at $9^{\circ} \mathrm{C} / \mathrm{min}$, and $200^{\circ} \mathrm{C}$ for $2 \mathrm{~min}$. Helium was used as a carrier gas with a constant column flow rate of $1 \mathrm{~mL} / \mathrm{min}$. The mass spectrometric detector (Varian Saturn 2000; Agilent Technology Inc., USA) was operated in electron impact (EI) mode at $70 \mathrm{eV}$ in a range of 15-210 amu. The tentative identifications were based on comparing the mass spectra of the unknown compounds with those in the Wiley mass spectral library (Registry of mass spectral data, $6^{\text {th }}$ edition, USA).

\section{Statistical Analysis}

All Dakgalbi samples were repeated five times for GC- 
MS analysis. Data sets of the contents of hexanal and octanal were analyzed by the Student's $t$ test. Differences between the contents according to cooking methods considered significant at $p<0.05$.

\section{Results and Discussions}

\section{Changes of volatile compounds in gamma-irradi- ated charcoal-broiled Dakgalbi}

To investigate the effect of charcoal broiling on the changes of volatile compounds in Dakgalbi according to gamma irradiation, Dakgalbi was charcoal-broiled and irradiated with absorbed doses of 0,10 and $20 \mathrm{kGy}$. SPME GC-MS analysis revealed that a total of 32 volatile compounds are identified as the major flavoring components of Dakgalbi (Fig. 1), including sulfur compounds such as allyl mercaptan, 3,3'-thiobis-1-propene, 4-thia1,6-heptadiene and allyl disulfide, aromatic compounds such as toluene, benzaldehyde and $o$-cymene, low molecular compounds such as pellandrene, carene, cryophillene, cedr-8-ene and tumorone, degraded compounds of lipids such as methylbutanal and hydroxybutanone, and hydrocarbons such as hexane, nonane, heptanal, octanal, nonanal, terpinene and tetradecene formed from lipids by the adsorption of energy during cooking.

Gamma-irradiation increased or decreased these volatiles formed in charcoal-broiled Dakgalbi. As the absorbed doses increased from $0 \mathrm{kGy}$ to $20 \mathrm{kGy}$, the volatiles such as octanal, n-nonanal, (E)-3-tetradecene, n-tetradecene and (Z)-cyclodecene proportionally increased, while the volatiles such as allyl mercaptan, 3-hydroxy-2-butanone, 4-thia-1,6-heptadiene, gamma-terpinene and allyl disulfide decreased (Table 1). Cha and Cadwallader (1995) has reported that gamma-irradiation applied to chicken enhanced the generation of hydrocarbons, aromatics, aldehydes, ketones and other volatile low molecules, and among these volatiles, hydrocarbons were the most abundant. However, these hydrocarbons do not affect food flavor as they have a high odor threshold. Our results also demonstrated that gamma-irradiation increased the hydrocarbons such as hexane, nonane, heptanal, octanal, nonanal, teripnene, tetradecene and cyclodecene formed in charcoal-broiled Dakgalbi (Table 1). This is attributed to the generation of hydrocarbons by high ionizing energy
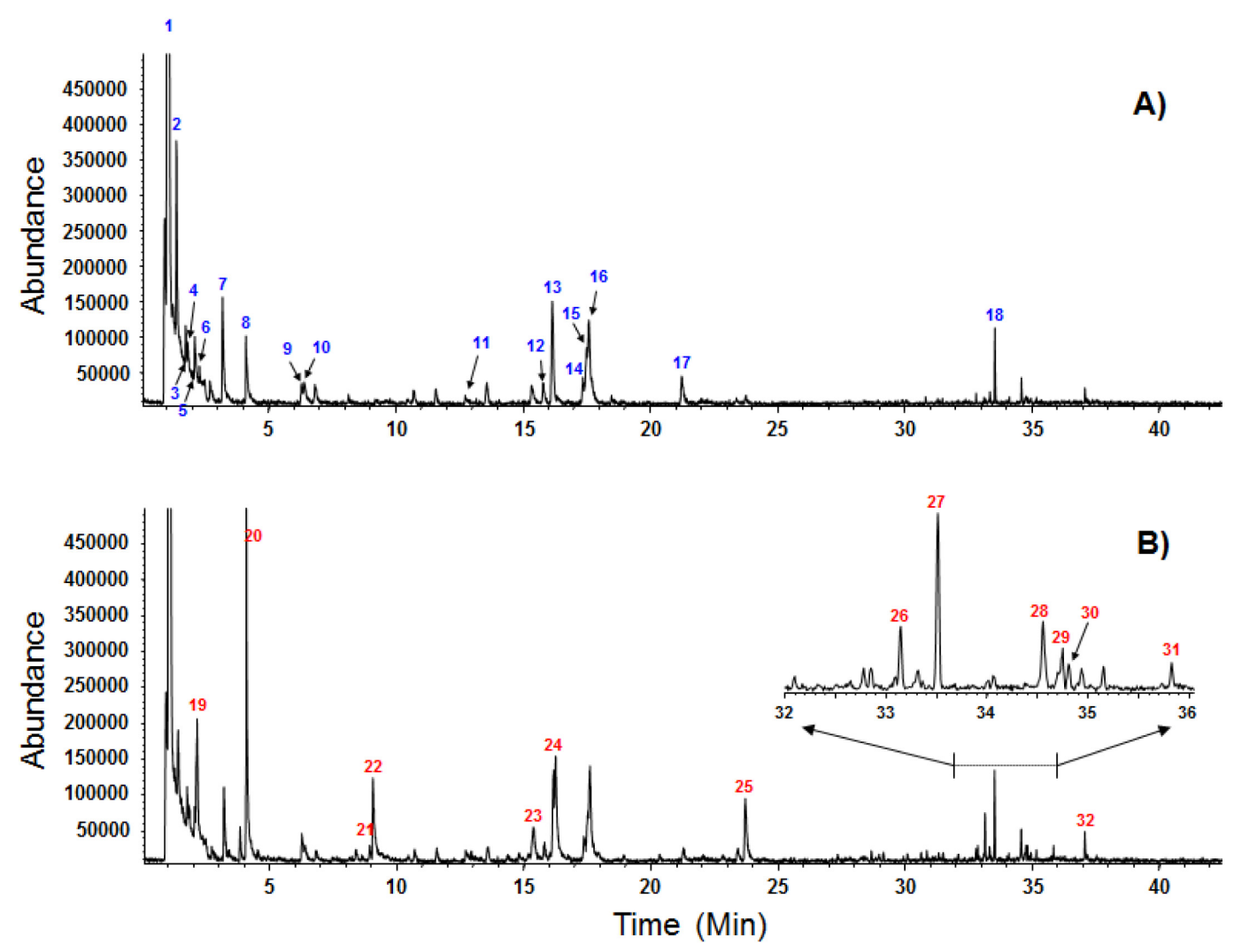

Fig. 1. SPME-GC chromatograms of cooked Dakgalbi by charcoal broiling after irradiation. (A) Non-irradiated Dakgalbi cooked by charcoal broiling, (B) 20 kGy gamma-irradiated Dakgalbi cooked by charcoal broiling. 
Table 1. Changes of volatile compound contents in cooked Dakgalbi by charcoal broiling after irridiation by SPME GC-MS analysis

\begin{tabular}{|c|c|c|c|c|c|c|}
\hline \multirow{2}{*}{ Peak No. } & \multirow{2}{*}{ Compound } & \multirow{2}{*}{ Peak Area ${ }^{a}$} & \multicolumn{3}{|c|}{$\mathrm{kGy}^{\mathrm{b}}$} & \multirow{2}{*}{ Remark } \\
\hline & & & 0 & 10 & 20 & \\
\hline 1 & Ethanol & $45,943,601 \pm 8,421,570$ & 1.0 & 1.00 & 1.30 & \\
\hline 2 & Allyl mercaptan & $10,944,533 \pm 4,006,218$ & 1.0 & 0.79 & 0.89 & \\
\hline 3 & 3-Methyl-butanal & $2,720,635 \pm 317,024$ & 1.0 & 0.96 & 1.53 & $\uparrow$ \\
\hline 4 & 2-Methyl-butanal & $2,336,992 \pm 242,394$ & 1.0 & 1.09 & 1.40 & $\uparrow$ \\
\hline 5 & Acetoin & $3,293,222 \pm 197,508$ & 1.0 & 1.19 & 0.86 & \\
\hline 6 & 3-Hydroxy-2-butanone & $33,387,627 \pm 5,619,084$ & 1.0 & 0.32 & - & $\downarrow$ \\
\hline 7 & Toluene & $3,495,281 \pm 521,730$ & 1.0 & 1.36 & 1.30 & \\
\hline 8 & 2-3-Butandiol & $4,985,634 \pm 361,085$ & 1.0 & 0.76 & 0.17 & $\downarrow$ \\
\hline 9 & 3,3'-Thiobis-1-propene & $765,745.1 \pm 81,007$ & 1.0 & 2.51 & 2.62 & $\uparrow$ \\
\hline 10 & 4-Thia-1,6-heptadiene & $630,278 \pm 74,806$ & 1.0 & 2.80 & 2.25 & $\uparrow$ \\
\hline 11 & Benzaldehyde & $391,419.3 \pm 49,567$ & 1.0 & 2.79 & 3.34 & $\uparrow$ \\
\hline 12 & 1-Phellandrene & $1,588,554 \pm 380,176$ & 1.0 & 1.19 & 1.10 & \\
\hline 13 & Delta-3-carene & $5,794,759 \pm 842,721$ & 1.0 & 1.3 & 1.18 & \\
\hline 14 & $o$-Cymene & $1,358,148 \pm 188,064$ & 1.0 & 1.41 & 1.60 & $\uparrow$ \\
\hline 15 & Gamma-terpinene & $3,840,498 \pm 251,094$ & 1.0 & 1.28 & 1.38 & \\
\hline 16 & DL-limonene & $7,592,047 \pm 541,231$ & 1.0 & 1.41 & 1.63 & $\uparrow$ \\
\hline 17 & Allyl disulfide & $1,746,814 \pm 218,022$ & 1.0 & 0.48 & 0.70 & $\downarrow$ \\
\hline 18 & Trans-cryophyllene & $376,360.9 \pm 91,874$ & 1.0 & 1.49 & 1.53 & $\uparrow$ \\
\hline 19 & 1-(methythio)-(E)-1-propene & $3,293,222 \pm 618,041$ & 1.0 & 1.28 & 0.79 & \\
\hline 20 & Hexanal & $2,147,523 \pm 117,029$ & 1.0 & 5.71 & 10.1 & $\uparrow$ \\
\hline 21 & N-Nonane & $-c$ & - & New $^{d}$ & New & $\uparrow$ \\
\hline 22 & Heptanal & $576,388 \pm 81,054$ & 1.0 & 4.75 & 9.42 & $\uparrow$ \\
\hline 23 & 1-Decene & $1,746,618 \pm 381,050$ & 1.0 & 1.83 & 2.38 & $\uparrow$ \\
\hline 24 & Octanal & $1,304,408 \pm 90,745$ & 1.0 & 2.93 & 6.27 & $\uparrow$ \\
\hline 25 & N-Nonanal & - & - & New & New & $\uparrow$ \\
\hline 26 & (E)-3-tetradecene & - & - & New & New & $\uparrow$ \\
\hline 27 & Caryophyllene & $1,973,637 \pm 310,861$ & 1.0 & 1.79 & 1.74 & $\uparrow$ \\
\hline 28 & AR-curcumene & $829,692 \pm 88,107$ & 1.0 & 1.74 & 2.07 & $\uparrow$ \\
\hline 29 & Cedr-8-ene & $406,914 \pm 32,170$ & 1.0 & 1.68 & 1.24 & \\
\hline 30 & N-Tetradecane & $177,000 \pm 18,940$ & 1.0 & 1.36 & 2.41 & $\uparrow$ \\
\hline 31 & (Z)-cyclodecene & - & - & - & New & $\uparrow$ \\
\hline 32 & AR-tumerone & $532,321 \pm 11,811$ & 1.0 & 1.70 & 2.17 & $\uparrow$ \\
\hline
\end{tabular}

${ }^{a}$ Peak area detected in non-irradiated charcoal-broiled Dakgalbi.

${ }^{\mathrm{b}}$ Relative peak area fold ratio of irradiated Dakgalbi to non-irradiated Dakgalbi.

${ }^{\mathrm{c}}$ Not detected.

${ }^{\mathrm{d}}$ Detected as a peak.

such as gamma-ray, which have one (Cn-1) or two (Cn2:1) carbon atoms less than the predominant fatty acids present in foods (Spiegelberg et al., 1994).

In general, fat present in meats contains various fatty acids such as palmitic acid, stearic acid, oleic acid and linoleic acid (Kim et al., 1999), and ionizing radiation can generate hydrocarbons having variable carbon chain lengths. Therefore, hydrocarbons have been suggested as an index substance for discriminating irradiated foods (Kim et al., 2002). However, as hydrocarbons can be generated by the cleavage of acyl-oxygen linkage or acyloxymethylene linkage of glycerol moiety ester bonded with fatty acids, or by the cleavage of covalent linkage between carbon atoms in fatty acids (LeTellier and Nawar, 1972; Nawar, 1978; Patterson and Stevenson, 1995), the mechanism of forming hydrocarbons in fat by the adsorption of energy is presumed to be rather extensive.

Irradiation can induce the formation of aromatic compounds such as alkyl-benzenes, naphthalenes and phenols (Cha et al., 2000). Although the mechanism of forcming alkyl-benzenes is not clear, Watanabe and Sato (1971) has shown that various alkyl-benzenes was formed in swallow fried beef, and toluene, xylene and benzene derivatives have been reported to be formed from carotenoids (Borenstein and Bunnell, 1966; Pippen et al., 1969). Jo and Ahn (2000) have also suggested that bovine 
serum albumin, gelatin and myofibril proteins might be precursors of the benzene derivatives. Supporting this, our results have shown that toluene, benzaldehyde and $o$ cymene were detected in non-irradiated charcoal-broiled Dakgalbi, and gamma-irradiation increased the generation of benzaldehyde (Table 1). However, toluene was not affected by gamma-irradiation.

Ho and Chen (1993) and Hansan et al. (1987) have shown that the irradiation of fresh chicken meats induced the formation of aldehydes. These aldehydes are known to be major volatile components formed by the auto-oxidation of unsaturated fatty acids and off-flavors such as green, paint, metallic, bean and rancid (Cha et al., 2000). The cause of the formation of aldehydes in irradiated charcoal-broiled Dakgalbi might be due to the acceleration of the oxidation of unsaturated fatty acids by free radicals generated during irradiation (Yook et al., 1998) and the increase of lipid rancidity by the cooking temperature and the time of charcoal broiling (Park et al., 2005). In this study, gamma-irradiation increased the aldehydes such as 3-methyl-butanal, 2-methyl-butanal, 3-hydroxy-2butanone, hexanal, heptanal, octanal, 1-decene, and n- nonane in charcoaled-broiled Dakgalbi (Table 1). Among the aldehydes, hexanal is known as an index substance in the oxidation and deterioration of foods and is formed by the auto-oxidation of 13-hydroperoxide and 15-hydroperoxide derived from unsaturated linoleic acid and arachidonic acid (Ho and Chen, 1993).

Volatiles such as caryophyllene, tumorone, curcumene, cymene and delta-3-carene, which were identified in this study, are the compounds originating from seasonings used for the preparation of charcoal-broiled Dakgalbi. In particular, caryophyllene and delta-3-carene are volatile compounds of black pepper (Plessi et al., 2002), and tumorone and curcumene are the principle ingredients of tumoric, which is a base of curry powder (Park et al., 1991). Cymene is a volatile derived from plants (Block et al., 1992).

\section{Effects of cooking method on the formation of hex-} anal and octanal in irradiated Dakgalbi

Next, to investigate the effect of the cooking method on the formation of volatile compounds in irradiated Dakgalbi, the samples were stir-fried in an electric-pan or

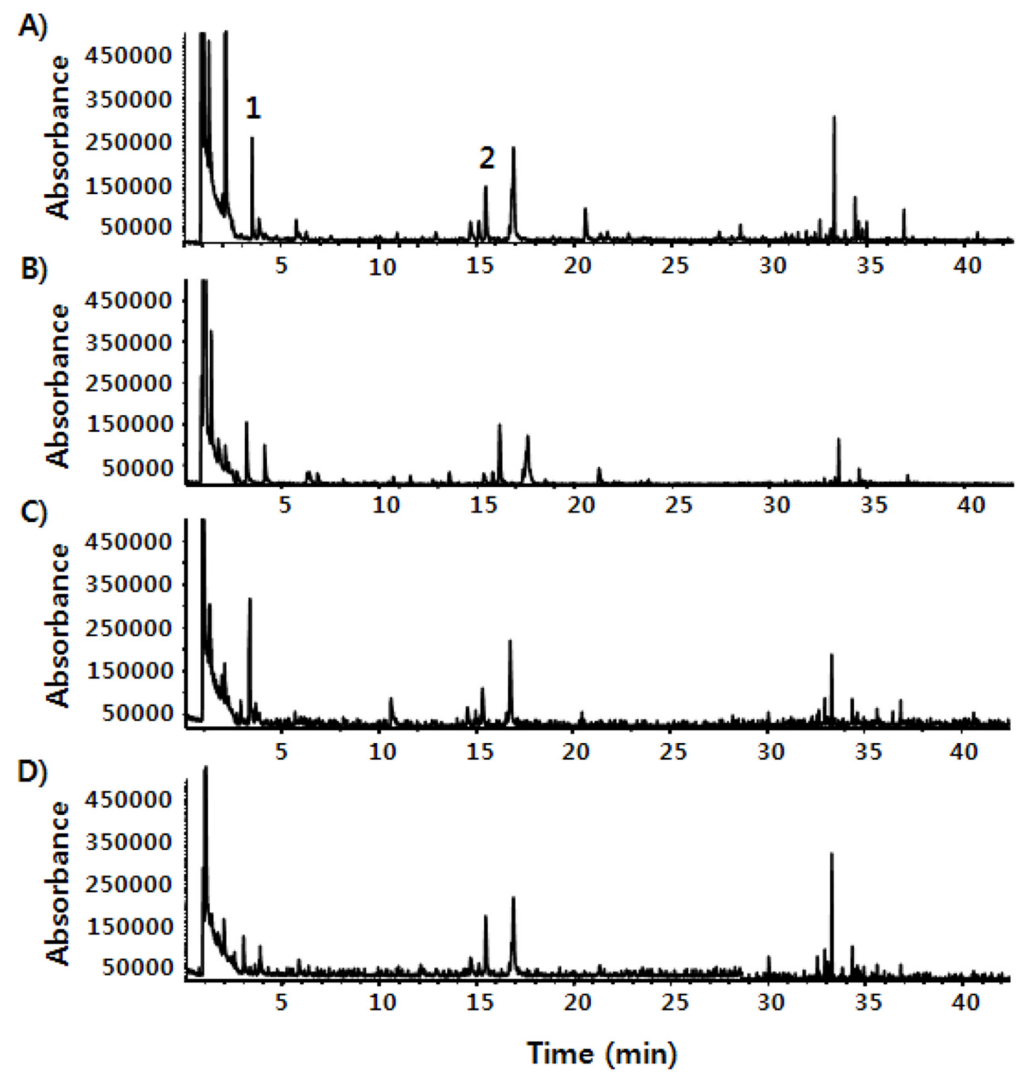

Fig. 2. SPME-GC chromatograms of volatile compounds from cooked Dakgalbi by electric-pan frying or charcoal broiling after irridiation. (A) Non-irradiated Dakgalbi cooked by electric-pan frying, 1. Hexanal, 2. Octanal, (B) Non-irradiated Dakgalbi cooked by charcoal broiling, (C) 20 kGy gamma-irradiated Dakgalbi cooked by electric-pan frying, (D) 20 kGy gamma-irradiated Dakgalbi cooked by charcoal broiling. 
Table 2. Changes of volatile compound contents in cooked Dakgalbi by electric-pan frying or charcoal broiling after irridiation by SPME GC-MS analysis

\begin{tabular}{|c|c|c|c|c|}
\hline \multirow{2}{*}{ PeakNo. } & \multirow{2}{*}{ Compound } & \multicolumn{2}{|c|}{ Cooking Methods $^{\mathrm{a}}$} & \multirow{2}{*}{ Remarks $^{\mathrm{b}}$} \\
\hline & & Electronic-pan frying & Charcoal broiling & \\
\hline \multicolumn{5}{|c|}{ A) non-irradiated Dakgalbi } \\
\hline 1 & Hexanal & $4,007,907 \pm 280,176^{\mathrm{A}}$ & $2,832,296 \pm 118,972^{\mathrm{B}}$ & 0.71 \\
\hline 2 & Octanal & $25,477,272 \pm 987,526^{\mathrm{A}}$ & $10,787,822 \pm 446,397^{\mathrm{B}}$ & 0.42 \\
\hline \multicolumn{5}{|c|}{ B) 20 kGy gamma-irradiated Dakgalbi } \\
\hline 1 & Hexanal & $42,674,782 \pm 1,897,624^{\mathrm{A}}$ & $5,514,941 \pm 882,591^{\mathrm{B}}$ & 0.13 \\
\hline 2 & Octanal & $69,438,262 \pm 2,591,428^{\mathrm{A}}$ & $38,418,351 \pm 3,948,627^{\mathrm{B}}$ & 0.55 \\
\hline
\end{tabular}

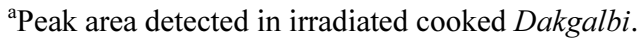

${ }^{\mathrm{b}}$ Relative peak area fold ratio of charcoal broiling to electric-pan frying.

${ }^{\mathrm{A}-\mathrm{B}}$ Mean values within a column follow by the different letter are significantly different $(p<0.05)$.

charcoal-broiled, and gamma-irradiated with an absorbed dose of $20 \mathrm{kGy}$. Among the volatile compounds identified using SPMC GC-MS analysis, the significant change of aldehydes such as hexanal and octanal were detected in both non-irradiated electric-pan-fried and charcoal-broiled Dakgalbi and the contents were 0.71- and 0.42-times less in the charcoal-broiled Dakgalbi than in the electric-panfried Dakgalbi, respectively (Fig. 2, Table 2A).

Gamma-irradiation caused a dramatic change in the contents of these volatiles in Dakgalbi. Gamma-irradiation increased the contents of hexanal and octanal in electric-pan-fried Dakgalbi, and a similar effect was also observed in charcoal-broiled Dakgalbi (Table 2A and 2B). However, the contents of hexanal and octanal were 0.13- and 0.55-times less in the charcoal-broiled Dakgalbi than in the electric-pan-fried Dakgalbi, respectively (Table 2B). This indicates that although gamma-irradiation causes the increase of the contents of these volatiles in Dakgalbi, a charcoal broiling method can reduce increasing range of aldehydes formed during cooking. The reason for this might be increasing the removal of lipid content in broiled Dakgalbi, which is cooked directly above charcoal fire, or facilitating the rapid decomposition of aldehydes such as hexanal and octanal formed during the cooking, as the temperature of charcoal broiling is much higher than that of electric-pan frying.

Recently, Yoon (2012) reported that the volatiles like aldehydes formed during gamma-irradiation can influence the sensory quality of Dakgalbi. The results showed that gamma-irradiation deteriorated the sensory quality of electric-pan-fried or charcoal-broiled Dakgalbi, and the effect was irradiating dose-dependent. However, the worsening of the sensory quality was significantly much less in charcoaled-broiled Dakgalbi than in electric-pan-fried Dakgalbi. Among the tested sensory evaluations, off-fla- vor was found to mostly affect the overall acceptability of Dakgalbi (Yoon, 2012), implying the possible involvement of aldehydes on its sensory quality. This indicates that charcoal broiling can be a better cooking method than electric-pan frying for the improvement of the organoleptic property of Dakgalbi.

As a conclusion, these results suggest that charcoal broiling might be more effective than electric-pan frying for the relative reduction of the contents of hexanal and octanal increased by gamma-irradiation.

\section{Acknowledgements}

This research was co-supported by the National Research Foundation in the Nuclear Research \& Development Program and by the Basic Research Support Program of Korea Atomic Energy Research Institute.

\section{References}

1. Ahn, H. J., Kim, J. H., Lee, J. W., Jo, C., and Byun, M. W. (2004) Application of gamma irradiation for the reduction of residual nitrite and nitrosamine in meat products. Korean $J$. Food Sci. An. 24, 367-372.

2. Block, E., Naganathan, S., Putman, D., and Zhao, S. H. (1992) Allium chemistry: HPLC analysis of thiosulfates from onion, garlic, chive, and Chinese chive. Uniquely high allyl to methyl ratios in some galric samples. J. Agric. Food Chem. 40, 2418-2430.

3. Borenstein, B., and Bunnell, R. H. (1966) Carotenoids: Properties, occurrence and utilization in foods. Food Res. 15, 195 276.

4. Cha, Y. J., and Cadwallader, K. R. (1995) Volatile components in salt-fermented fish and shrimp pastes. J. Food Sci. 60, 1924.

5. Cha, Y. J., Kim, H., Park, S. Y., Cho, W. J., Yoon, S. S., and You, Y. J. (2000) Identification of irradiated-induced volatile 
flavor compounds in chicken. J. Korean Soc. Food Sci. Nutr. 29, 1050-1056.

6. Farkas, J. (2006) Irradiation for better foods. Trends Food Sci. Technol. 17, 148-152.

7. Gomes, H. A., Silva, E. N., Cardello, H. M. A. B., and Cipoli, K. M. V. A. B. (2003) Effect of gamma radiation on refrigerated mechanically deboned chicken meat quality. Meat Sci. 65, 919-926.

8. Hansen, T. J., Chen, G. C., and Shieh, J. J. (1987) Volatiles in skin of low-dose irradiated fresh chicken. J. Food Sci. 52, $1180-1182$.

9. Ho, C. T., and Chen, Q. (1993) Lipids in food flavors. In: Lipids in Food Flavors, Ho, C. T., and Hartman, T. G. (eds.) American Chemical Society, Washington, DC, pp. 2-14.

10. Javanmard, M., Rokin, N., Bokaie, S., and Shahhosseini, G. (2006) Effect of gamma irradiation and frozen storage on microbial, chemical and sensory quality of chicken meat in Iran. Food Control 17, 469-473.

11. Jo, C., and Ahn, D. U. (2000) Production of volatile compounds from irradiated oil emulsion containing amino acids or proteins. J. Food Sci. 65, 612-616.

12. Kim, K. S., Kim, E. A., Lee, H. J., Yang, J. S., and Byun, M. W. (1999) Quantitative comparison of radiation-induced hydrocarbons from irradiated beef, pork and chicken. Korean $J$. Food Sci. Technol. 31, 301-307.

13. Kim, H., Cho, W. J., Jung, Y. J., Lee, Y. M., Jeong, E. J., Yoo, Y. J., Byun, M. W., and Cha, Y. J. (2002) Irradiation induced volatile compounds in irradiated chicken by P\&T method. Korean J. Food Sci. Technol. 31, 958-964.

14. LeTellier, P. R., and Nawar, W. W. (1972) Primary radiolytic fragmentation in tricaproin. J. Agric. Food Chem. 20, 129-134.

15. McKay, A. L., Peters, A. C., and Hann, A. C. (1997) The growth of Salmonella typhimurium on irradiated raw skinless chicken breast. Int. J. Food Microbiol. 37, 121-129.

16. Nawar, W. W. (1978) Reaction mechanism in the radiolysis of fats: A review. J. Agric. Food Chem. 26, 21-25.

17. Park, T. S., Shin, T. S., Lee, J. I., and Park, G. B. (2005) Effects of cooking method and temperature on the lipid oxidation of electron-beam irradiated Hanwoo Steak. J. Life Sci. 15, 840846.

18. Park, W. K., Yoon, J. H., Kim, H. W., and Choi, C. U. (1991) The effects of stamping and roasting treatments on volatile aromatic components in curry powder. Korean J. Food Sci. Technol. 23, 276-279.

19. Patterson, R. L. S., and Stevenson, M. H. (1995) Irradiationinduced off-odour in chicken and its possible control. Brit.
Poult. Sci. 36, 425-441.

20. Pippen, E. L., Mecchi, E. P., and Nonaka, M. (1969) Origin and nature of aroma in fat of cooked poultry. J. Food Sci. 34, 436-442.

21. Plessi, M., Bertelli, D., and Miglietta, F. (2002) Effect of microwaves on volatile compounds in white and black pepper. LWT-Food Sci. Technol. 35, 260-264.

22. Rajkowski, K. T., and Thayer, D. W. (2000) Reduction of Salmonella spp. and strains of Escherichia coli 0157:H7 by gamma radiation of inoculated sprouts. J. Food Prot. 63, 871875 .

23. Serrano, L. E., Murano, E. A., Shenoy, K., and Olson, D. G. (1997) D values of Salmonella enteritidis isolates and quality attributes of shell eggs and liquid whole eggs treated with irradiation. Poultry Sci. 76, 202-205.

24. Spiegelberg, A., Schulzki, G., Helle, N., Boegl, K. W., and Schreiber, G. A. (1994) Methods for routine control of irradiated food: Optimization of a method for detection of radiationinduced hydrocarbons and its application to various foods. Radiat. Phy. Chem. 43, 433-444.

25. Watanabe, K., and Sato, Y. (1971) Some alkyl-substituted pyrazines and pyridines in the flavor components of shallow fried beef. J. Agric. Food Chem. 19, 1017-1019.

26. WHO (1999) High dose irradiation: wholesomeness of food irradiated with doses above $10 \mathrm{kGy}$. WHO Technical Report Series 890

27. Yook, H. S., Lee, K. H., Lee J. W., Kang, K. O., and Byun, M. W. (1998) Effect of gamma irradiation on lipid oxidation of Korean beef. Korean J. Food Sci. Technol. 30, 1179-1183.

28. Yoon, Y. H., Cho, W. J., Park, J. G., Park, J. N., Song, B. S., Kim, J. H., Byun, M. W., Kim, C. J., Sharma, A. K., and Lee, J. W. (2009) Effect of gamma irradiation on shelf-life extension and sensory characteristics of Dakgalbi (marinated diced chicken) during accelerated storage. Korean J. Food Sci. An. 29, 573-578.

29. Yoon, Y. M., Park, J. H., Lee, J. H., Park, J. N., Park, J. K., Sung, N. Y., Song, B. S., Kim, J. H., Yoon Y., Gao, M., Yook, H. S., and Lee, J. W. (2012) Effects of gamma-irradiation before and after cooking on bacterial population and sensory quality of Dakgalbi. Radiat. Phy. Chem. 81, 1121-1124.

30. Yoon, Y. M. (2012) Studies on the identification of volatile compounds of high dose irradiated ready-to-eat chicken and improvement of its organoleptic qualities. MS thesis, Chungnam Nat'l Univ., Daejeon, Korea.

$\overline{\text { (Received 2013.7.18/Revised 2013.10.2/Accepted 2013.10.8) }}$ 